02

\title{
Фотолиз диазокрасителя в растворах и покрытиях, содержащих оксидные соединения цинка и серебра
}

\author{
() О.В. Истомина ${ }^{1}$, С.К. Евстропьев ${ }^{2}$, Е.В. Колобкова ${ }^{1,2}$, А.О. Трофримов ${ }^{2}$ \\ ${ }^{1}$ Санкт-Петербургский государственный технологический институт (технический университет), \\ 190013 Санкт-Петербург, Россия \\ ${ }^{2}$ Университет ИТМО, \\ 197101 Санкт-Петербург, Россия \\ e-mail: evstropiev@bk.ru
}

Поступила в редакцию 20.12.2017 г.

В окончательной редакции 15.02.2018 г.

\begin{abstract}
Экспериментально исследован фотолиз диазокрасителя Chicago Sky Blue в водных растворах и покрытиях, содержащих оксидные соединения цинка и серебра. Присутствие нитратов цинка и серебра в водных растворах этого красителя значительно увеличивают скорость его фотолиза под действием УФ излучения. Оксидные пленки $\mathrm{ZnO}, \mathrm{ZnO}: \mathrm{Ag}$ и композиционные покрытия, содержащие нитраты цинка и серебра, также оказывают заметное влияние на процессы фотолиза диазокрасителя Chicago Sky Blue.
\end{abstract}

DOI: $10.21883 /$ OS.2018.06.46074.298-17

\section{Введение}

Фотокаталитические свойства различных материалов являются предметом интенсивных исследований [1-5]. В значительной мере это связано с разработкой новых материалов и покрытий, обладающих новым сочетанием функциональных свойств (оптических, фотокаталитических, бактерицидных) [2-8]. Кроме того, совершенствование методов УФ обработки воздуха, водных сред, обеззараживания поверхности твердых материалов и удаления органических загрязнений является актуальной экологической проблемой [3,7,9-11].

В настоящее время много работ посвящено разработке фотокаталитических и бактерицидных материалов на основе оксидных соединений цинка $[1,2,4,6,8,13-16]$. Низкая стоимость этих материалов и высокие фотокаталические свойства определяют их перспективность для широкого практического применения. В $[2,6,13]$ было показано, что функциональные характеристики оксидных соединений цинка можно дополнительно существенно улучшить путем введения добавок оксидных соединений других металлов (Ag, Ce, Ti).

Диазокрасители довольно широко используются в промышленности, и разработка методов очистки воды от этих красителей является актуальной проблемой $[3,12]$. Растворы диазокрасителя Chicago Sky Blue (CSB) используются для оценки фотокаталитических свойств различных материалов $[4,11,12,17,18]$. Спектральные свойства этого красителя хорошо известны [19], а структура его молекулы приведена в [4]. В работе [4] нами было показано, что присутствие нитратов металлов в растворах CSB изменяет механизм фотолиза и резко увеличивает его скорость.

Целью настоящей работы являлось экспериментальное исследование процессов фотокаталитического раз- ложения диазокрасителя в растворах и покрытиях, содержащих оксидные соединения цинка и серебра.

\section{Материалы и методика эксперимента}

В качестве объектов исследования в работе использовались водные растворы нитратов цинка и серебра, а также водный раствор органического красителя CSB 6B (Sigma Aldrich). Предварительно взвешенные навески порошков растворялись при перемешивании в дистиллированной воде. Полученные растворы смешивались между собой или при добавлении воды в заданных пропорциях.

Введение в состав пленкообразующих растворов высокомолекулярного поливинилпирролидона (ПВП) $\left(M_{w}=1300000\right.$, Sigma Aldrich) обеспечивает получение на поверхности стекол однородных и прозрачных в видимой части спектра композиционных покрытий [20]. Поэтому в настоящей работе в состав пленкообразующих растворов, содержащих диазокраситель, добавлялся раствор этого полимера в пропаноле-2. Нанесение покрытий осуществлялось путем погружения стеклянных образцов в пленкообразующий раствор с последующим их извлечением и сушкой. Полученные композиционные пленки, содержащие нитраты металлов и ПВП, характеризовались высокой однородностью.

Для формирования оксидных пленок на поверхности стекол образцы с композиционными покрытиями подвергались термообработке в лабораторной электропечи при температуре $550^{\circ} \mathrm{C}$ в течение $2 \mathrm{~h}$. Использование такой методики обеспечивает формирование прозрачных и однородных покрытий, состоящих из оксидных наночастиц [21]. Толщина композиционных покрытий составляла $300-600 \mathrm{~nm}$. 

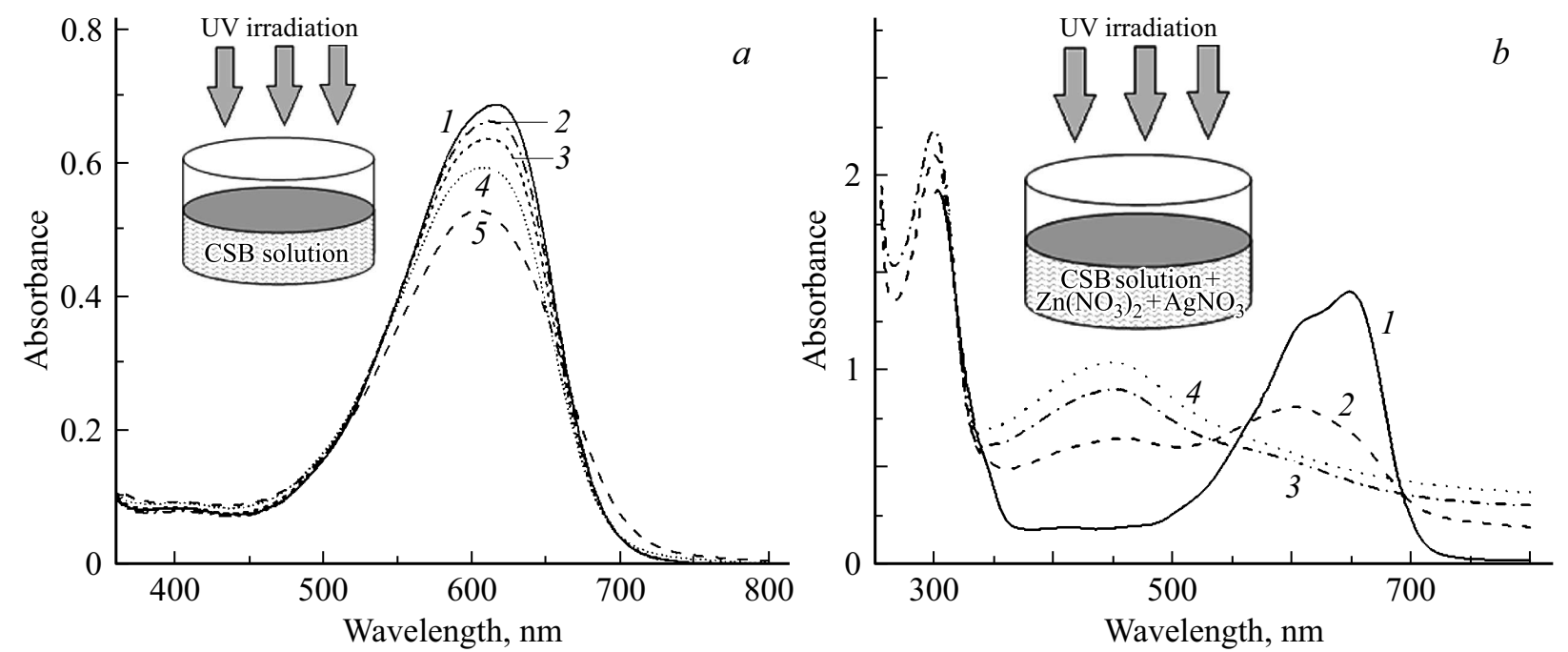

Рис. 1. (a) Изменения спектров поглощения водных растворов $\mathrm{CSB}$, содержащих $\mathrm{Zn}\left(\mathrm{NO}_{3}\right)_{2}$ под действием УФ излучения ртутной

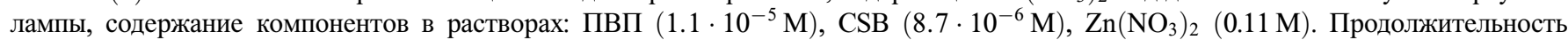
облучения: 5 (2), 10 (3), 20 (4), $30 \mathrm{~min}$ (5). Исходный раствор - 1. (b) Изменения спектров поглощения водных растворов $\mathrm{CBS}$, содержащих $\mathrm{Zn}\left(\mathrm{NO}_{3}\right)_{2}$ и $\mathrm{AgNO}_{3}$ под действием УФ излучения ртутной лампы, содержание компонентов в растворах: ПВП $\left(1.1 \cdot 10^{-5} \mathrm{M}\right), \mathrm{CSB}\left(8.7 \cdot 10^{-6} \mathrm{M}\right), \mathrm{Zn}\left(\mathrm{NO}_{3}\right)_{2}(0.11 \mathrm{M}), \mathrm{AgNO}_{3}(0.06 \mathrm{M})$. Продолжительность облучения: 15 (2), 30 (3), 45 (4). Исходный раствор -1 .

Для оценки фотокаталитических свойств полученных оксидных пленок на их поверхность методом погружения в водный раствор наносились композиционные покрытия CBS/ПВП. Использование растворов, содержащих ПВП, обеспечивало однородность распределения красителя на поверхности образцов.

Регистрация спектров поглощения растворов осуществлялась в кварцевых кюветах на спектрофотометре Perkin-ElmerLabda 650. Облучение растворов осуществлялось ртутной лампой высокого давления ДРТ-240. Спектр излучения этой лампы приведен в [22]. Плотность мощности излучения при облучении образцов составляла $0.25 \mathrm{~W} / \mathrm{cm}^{2}$.

Исследование морфологии и толщины оксидных покрытий проводилось методом сканирующей электронной микроскопии на приборе TescanVega 3 SBH. Для определения толщины оксидных покрытий использовались электронно-микроскопические снимки среза покрытий. Толщина оксидных покрытий составляла $150-200 \mathrm{~nm}$.

\section{Экспериментальные результаты и их обсуждение}

Рис. 1 иллюстрирует изменения в спектрах поглощения при фоторазложении CSB в водном растворе (рис. 1,a), а также растворах этого красителя, смеси нитратов цинка и серебра (рис. $1, b$ ). В спектрах растворов до облучения наблюдается несколько отличная форма интенсивной полосы поглощения в видимой части спектра. Это различие обусловлено как некоторой разни- цей в содержании красителя в растворах, так и влиянием содержащихся в них катионов металлов.

По данным [19] при содержании CSB в водном растворе более $10^{-7}-10^{-6} \mathrm{M}$ могут активно протекать процессы межмолекулярного взаимодействия и происходить образование димеров и тримеров молекул красителя. Это определяет усложнение структуры и изменение интенсивности полосы поглощения в видимом диапазоне и проявление в ее длинноволновой части перегиба или дополнительного максимума (рис. 1). На основании $[4,23]$ можно предположить, что изменению структуры этой полосы поглощения может способствовать также наличие в растворе ионов металлов, способных к образованию комплексов с молекулами CSB.

Из сопоставления данных, полученных при облучении различных растворов, можно сделать вывод о том, что присутствие в растворах нитратов цинка и серебра значительно ускоряет процесс фотолиза красителя и существенно изменяет характер изменений, наблюдаемых в спектрах поглощения растворов.

В спектрах поглощения растворов, содержащих добавки нитратов, хорошо видна полоса поглощения в УФ части спектра с максимумом $\lambda_{\max } \sim 300 \mathrm{~nm}$. Эта полоса является результатом наложения полосы поглощения анионов $\mathrm{NO}_{3}^{-}$и поглощения молекулами красителя. Под действием УФ излучения в растворах происходит разложение анионов $\mathrm{NO}_{3}^{-}[9,24]$, сопровождающееся выделением химически активных продуктов, способных, в свою очередь, участвовать в разложении органических соединений [9]. Можно предположить, что именно эти процессы с участием анионов $\mathrm{NO}_{3}^{-}$определяют наблю- 

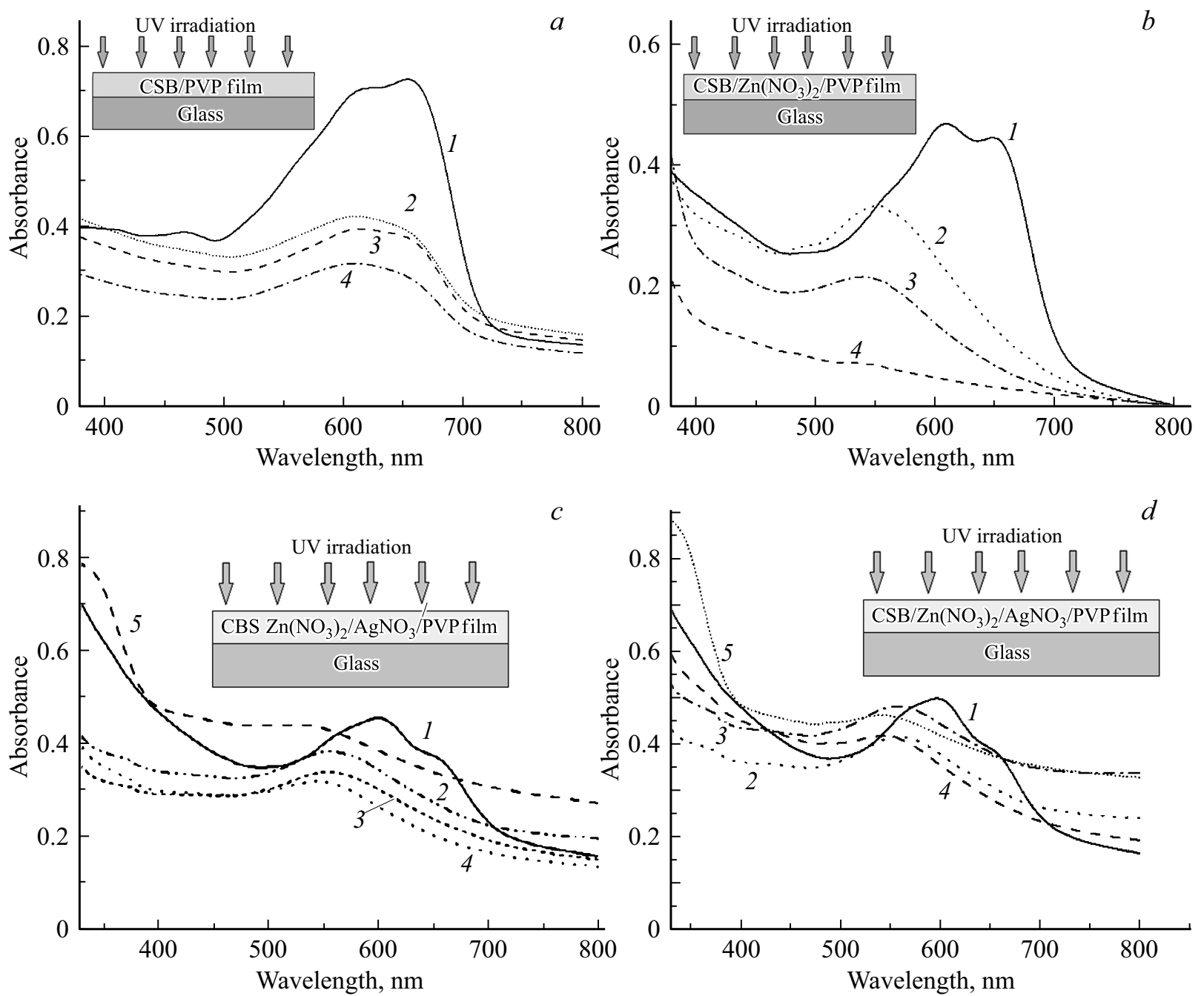

Рис. 2. (а) Изменения спектров поглощения пленки CSB/ПВП (CSB 0.06 wt.\%, ПВП 99.94 wt.\%), нанесенной на поверхность стекла при облучении ртутной лампой: до облучения (1), после облучения в течение $10(2), 20(3), 30 \mathrm{~min}(4)$. (b) Изменения спектров поглощения при облучении ртутной лампой образцов стекла с композиционным покрытием $\left.\mathrm{PVP} / \mathrm{Zn}(\mathrm{NO})_{2}\right)_{2}$, поверх которого нанесена пленка $\mathrm{CSB} /$ ПВП (CSB 0.02 wt.\%, $\mathrm{Zn}\left(\mathrm{NO}_{3}\right)_{2} 59.39 \mathrm{wt} . \%$, ПВП $40.59 \mathrm{wt} \%$ ): до облучения (1), после облучения в течение 10 (2), 20 (3), $30 \mathrm{~min}(4)$. (c) Изменения спектров поглощения при облучении ртутной лампой образцов стекла с композиционным покрытием $\mathrm{PVP} / \mathrm{Zn}\left(\mathrm{NO}_{3}\right)_{2} / \mathrm{AgNO}_{3}$, поверх которого нанесена пленка CSB/ПВП (CSB 0.02 wt.\%, $\mathrm{Zn}\left(\mathrm{NO}_{3}\right)_{2} 57.75 \mathrm{wt} \%, \mathrm{AgNO}_{3} 2.76 \mathrm{wt} . \%$, ПВП $\left.39.47 \mathrm{wt} . \%\right)$ : до облучения (1), после облучения в течение 10 (2), 20 (3), 30 (4), $40 \min (5) .(d)$ Изменения спектров поглощения при облучении ртутной лампой образцов стекла с композиционным покрытием $\mathrm{PVP} / \mathrm{Zn}\left(\mathrm{NO}_{3}\right)_{2} / \mathrm{AgNO}_{3}$, поверх которого нанесена пленка CSB/ПВП (CSB 0.02 wt.\%, Zn( $\left.\mathrm{NO}_{3}\right)_{2} \quad 56.07$ wt.\%, AgNO 3.59 wt.\%, ПВП 38.32 wt.\%): до облучения (1), после облучения в течение 10 (2), 20 (3), 30 (4), 40 min (5). Структура образцов показана на вставках в рисунки.

даемое значительное ускорение фотолиза диазокрасителя в присутствии нитратов металлов.

Под действием УФ излучения происходит быстрое изменение окраски растворов. Интенсивность полосы поглощения CSB в видимой части спектра уменьшается, a ее максимум сдвигается в коротковолновую часть спектра. Сопоставление изменений, наблюдаемых при УФ облучении в спектрах поглощения растворов, содержащих смесь нитратов цинка и серебра (рис. 1,b), показывает, что введение в раствор нитрата серебра не оказывает заметного влияния на скорость фотоли- за. Видно также, что в присутствии ионов серебра в спектрах облученных растворов (рис. 1,a) наблюдается характерная плазмонная полоса поглощения наночастиц серебра с $\lambda_{\max } \sim 450 \mathrm{~nm}$ [25]. Можно предположить, что присутствие в растворах ПВП, выполняющего роль поверхностно-активного вещества, способствует стабилизации этих наночастиц.

Рис. 2 иллюстрирует изменения в спектрах поглощения при фоторазложении красителя в композиционных пленках CSB/ПВП, нанесенных на поверхность стекла (рис. 2,a), а также на поверхность предваритель- 


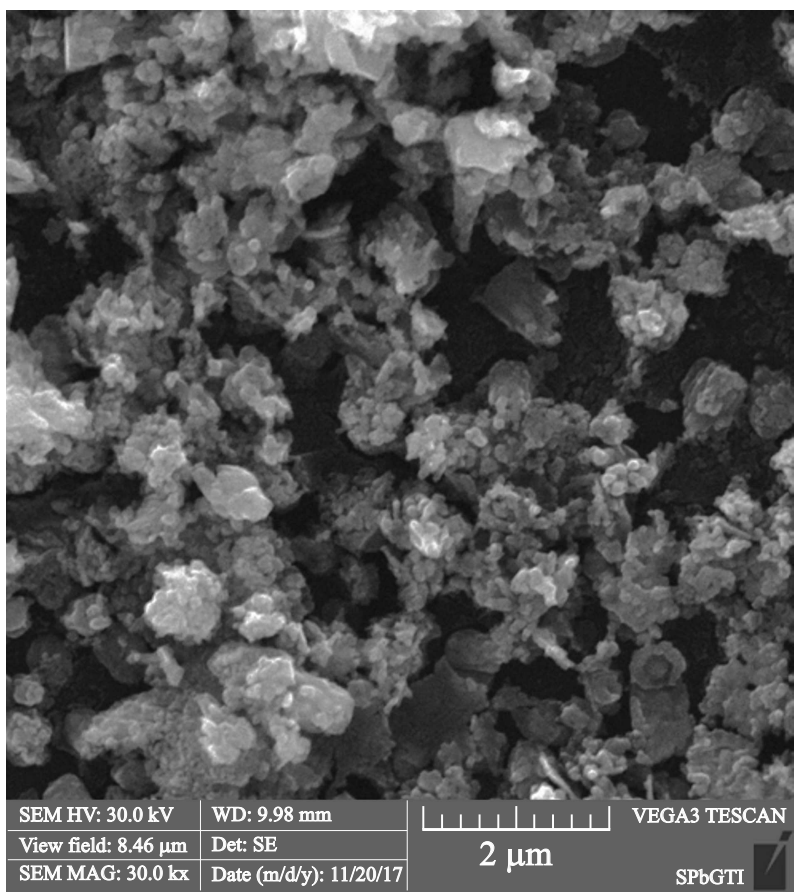

Pис. 3. Электронно-микроскопическое изображение поверхности покрытия $\mathrm{ZnO}: \mathrm{Ag}$ на поверхности стекла. Покрытие содержит $\mathrm{ZnO} 86.3$ wt.\%, $\mathrm{Ag}_{2} \mathrm{O} 13.7$ wt.\%.

но изготовленных покрытий ПВП/ $\mathrm{Zn}\left(\mathrm{NO}_{3}\right)_{2}$ (рис. $\left.2, b\right)$ и ПВП/Zn $\left(\mathrm{NO}_{3}\right)_{2} / \mathrm{AgNO}_{3}$ (рис. 2, $\left.c, d\right)$. Предварительно нанесенные на поверхность стекла композиционные полимерно-солевые покрытия были однородными и прозрачными в видимом спектральном диапазоне (рис. 2, $a$, кривая 1).

Нанесение на поверхность этого покрытия пленки c CSB привело к появлению в спектре поглощения образца характерной для этого красителя полосы поглощения в области 600-670 nm (рис. 2, a, кривая 2). При нанесении из раствора пленки, содержащей ПВП и $\mathrm{CSB}$, и ее последующей сушке происходит испарение растворителя и концентрация красителя в пленке по сравнению с раствором значительно возрастает. Это определяет наблюдаемую форму полосы поглощения, характеризующуюся наличием двух близко расположенных максимумов. Облучение образца с этим покрытием приводит к фотолизу красителя, интенсивность полосы поглощения в спектрах уменьшается (рис. 2, $a$ ), а синяя окраска образца заметно бледнеет и становится голубой.

При УФ облучении в спектрах поглощения облученных образцов с композиционным покрытием, состоящим из ПВП и нитрата цинка, сильно уменьшается интенсивность полосы поглощения диазокрасителя, а ее максимум существенно сдвигается в коротковолновую часть спектра (рис. 2,b). Фотолиз красителя приводит к сильному изменению окраски образцов с синей на розовую. Наблюдаемое различие в спектрах поглощения образцов свидетельствует о том, что, несмотря на экранирующее действие внешнего покрытия $\mathrm{CSB} /$ ПВП, УФ излучение достигает находящейся под ним полимерно-солевой пленки, и протекающие в ней фотохимические процессы оказывают существенное влияние на фотолиз красителя во внешнем покрытии.

Облучение ртутной лампой образцов с композиционным покрытием ПВП/Zn $\left(\mathrm{NO}_{3}\right)_{2} / \mathrm{AgNO}_{3}$, поверх которого нанесены пленки $\mathrm{CSB} /$ ПВП, привело к значительному изменению их спектров поглощения (рис. 2, $c, d$ ). В спектрах облученных образцов наблюдаются снижение интенсивности полосы поглощения красителя и сдвиг ее максимума в коротковолновую часть спектра. В результате воздействия УФ излучения происходит существенная деформация формы спектров из-за сильного увеличения поглощения в их коротковолновой
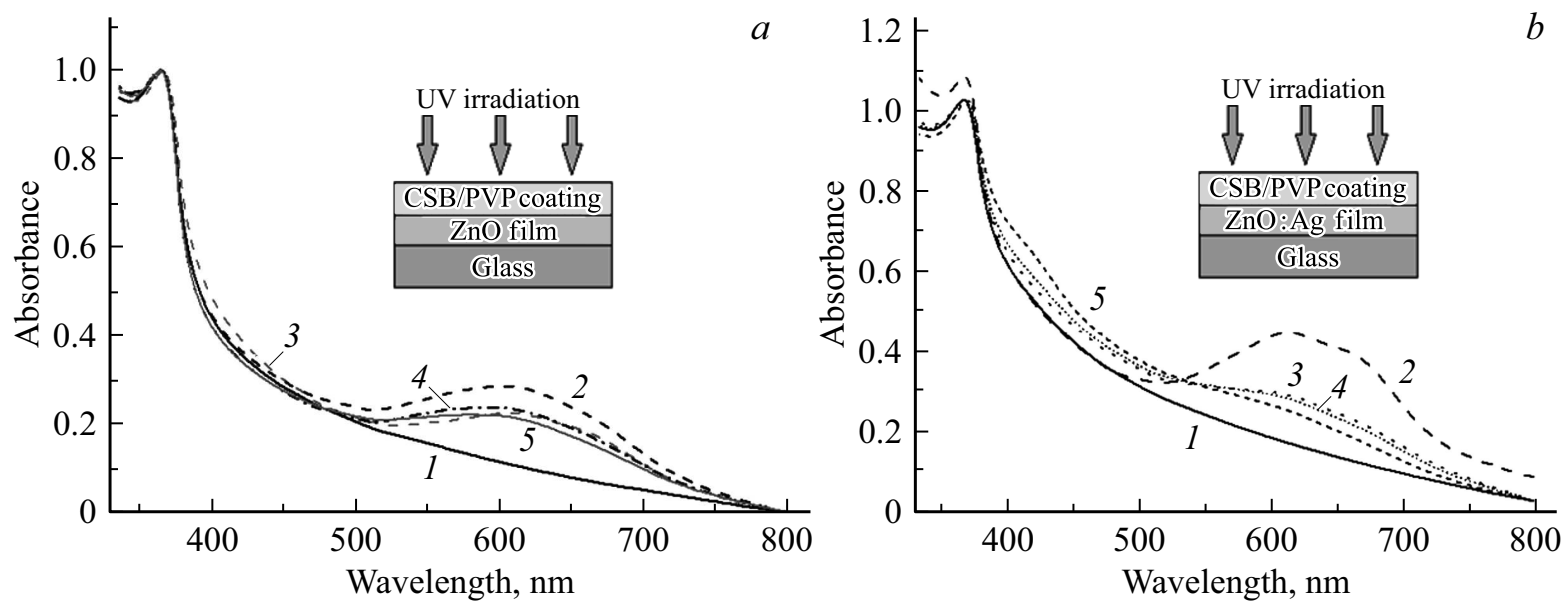

Рис. 4. Изменения спектров поглощения образцов с композиционным покрытием CBS/ПВП, нанесенным поверх оксидных пленок $\mathrm{ZnO}(a)$ и $\mathrm{ZnO}: \mathrm{Ag}(b)$ на поверхности стекла. Покрытие $\mathrm{ZnO}: \mathrm{Ag}$ содержит $\mathrm{ZnO} 86.3$ wt.\%, $\mathrm{Ag}_{2} \mathrm{O} 13.7$ wt.\%. Структура образцов показана на вставках в рисунки. Спектры исходных оксидных покрытий (1). Спектры образцов после нанесения на поверхность оксидных покрытий пленок, содержащих ПВП и краситель (2). Спектры образцов после УФ облучения в течение 10 (3), 20 (4) и $30 \mathrm{~min}(5)$. 
части. При УФ облучении образцов с покрытиями $\Pi \mathrm{B} / \mathrm{Zn}\left(\mathrm{NO}_{3}\right)_{2} / \mathrm{AgNO}_{3}$ их окраска изменяется от синей к серой.

Изменение содержания нитрата серебра в композиционной пленке ПВП/Zn $\left(\mathrm{NO}_{3}\right)_{2} / \mathrm{AgNO}_{3}$ практически не оказывает влияния на характер эволюции диазокрасителя при фотообработке (рис. 2, $c, d$ ). Отсутствие этого влияния может объясняться относительно высоким содержанием нитратов цинка и серебра в полимерносолевой пленке. Данные рис. $2, c, d$ показывают, что введение в состав этой пленки более 2 вес.\% нитрата серебра является избыточным для дополнительного ускорения фотолиза диазокрасителя.

На рис. 3 представлено электронно-микроскопическое изображение покрытия $\mathrm{ZnO}: \mathrm{Ag}$, сформированного на поверхности стекла. Видно, что материал покрытия состоит из субмикронных агрегатов, образованных частицами, имеющими размер около $100 \mathrm{~nm}$. Такая структура покрытия обеспечивает высокую удельную поверхность материала и возможность активного взаимодействия с окружающей средой.

Нанесение на поверхность оксидных пленок тонкого покрытия CBS/ПВП приводит к появлению в спектре характерных для этого красителя полос поглощения (рис. 4). Облучение УФ светом приводит к быстрому разложению красителя и уменьшению интенсивности полосы поглощения в видимой части спектра. Вместе с тем наблюдается небольшое увеличение поглощения в синей части спектра, более сильно проявляющиеся в пленках на поверхности покрытий $\mathrm{ZnO}: \mathrm{Ag}$. Из сопоставления рис. $4, a, b$ видно, что скорости фотолиза красителя в пленках на поверхности покрытий $\mathrm{ZnO}$ и $\mathrm{ZnO}: \mathrm{Ag}$ примерно одинаковы.

В УФ области в спектрах образцов с оксидными покрытиями наблюдается характерная для $\mathrm{ZnO}$ экситонная полоса поглощения с максимумом $\lambda_{\max }=370 \mathrm{~nm}$ [26]. Известно [16], что под действием УФ излучения с $\lambda \sim 365 \mathrm{~nm}$ наночастицы $\mathrm{ZnO}$ выделяют различные химически активные соединения кислорода (пероксидные и гидроксидные радикалы, синглетный кислород), активно разлагающие соприкасающиеся с оксидом цинка органические соединения. Учитывая широту спектра излучения ртутной лампы в УФ области спектра, можно полагать, что эти процессы оказывают влияние на разложение диазокрасителя в пленке, нанесенной на поверхность оксидного покрытия.

\section{Выводы}

Проведенные экспериментальные исследования показали, что оксидные соединения цинка и серебра оказывают существенное влияние на процессы фотолиза диазокрасителя CSB. Присутствие нитратов цинка и серебра в водных растворах этого красителя значительно увеличивают скорость его фотолиза под действием УФ излучения. Оксидные пленки $\mathrm{ZnO}$ и $\mathrm{ZnO}: \mathrm{Ag}$ и композиционные покрытия, содержащие нитраты цинка и серебра, также оказывают заметное влияние на процессы фотолиза диазокрасителя CSB.

Авторы выражают благодарность за проведение электронно-микроскопических исследований А.А. Горюнову (Сервисный Центр СПБГТИ (ТУ)). Результаты получены при использовании оборудования ИЦ СПбГТИ(ТУ) в рамках проекта 11.5884.2017/ИТР. Работа выполнена при финансовой поддержке Министерства образования и науки Российской Федерации (Проект 16.1651.2017/4.6)

\section{Список литературы}

[1] Киселев В.М., Евстропьев С.К., Стародубцев А.М. // Опт. и спектр. 2017. Т. 123. № 5. С. 798-805; Kiselev V.M., Evstropiev S.K., Starodubtsev A.M. // Opt. Spectrosc. 2017. V. 123. N 5. P. $809-815$.

[2] Karunakaran C., Rajeswari V., Gomathisankar P. // Sol. St. Sci. 2011. V. 13. P. 923-928.

[3] Zulkarnain Zainal, Lee Kong Hui, Mohd Zobir Hussein, Yun Hin Taufiq-Yap, Abdul Halim Abdullah, Irmati Ramli // J. Hazard. Mater. B. 2005. V. 125. P. 113-120.

[4] Волкова Н.А., Евстропьев С.К., Истомина О.В., Колобкова E.B. // Опт. и спектр. 2018. Т. 122. № 4. С. 472.

[5] Basnet P., Larsen G.K., Jadeja R.P., Hung Y.-C., Zhao Y. // ACS Appl. Mat. Interf. 2013. V. 5. P. 2085-2095.

[6] Evstropiev S.K., Karavaeva A.V., Dukelskii K.V., Kiselev V.M., Evstropyev K.S., Nikonorov N.V., Kolobkova E.V. // Ceramics International. 2017. V. 43. P. 14504-14510.

[7] Guldin S., Kohn P., Stefik M., Song J., Divitini G., Ecarla F., Ducati C., Wiesner U., Steiner U. // Nano Lett. 2013. V. 13. P. 5329-5335.

[8] Волынкин В.М., Евстропьев С.К., Караваева А.В., Дукельский К.В., Киселев В.М., Быков М.В., Евстропьев К.С. // Оптический журнал. 2017. Т. 84. № 7. C. 59-63; Volynkin V.M., Evstropiev S.K., Karavaeva A.V., Dukelskii K.V., Kiselev V.M., Bykov M.V., Evstropyev K.S. // J. Opt. Technol. 2017. V. 84. N 7. P. 477-480.

[9] Minero C., Chiron S., Falletti G., Maurino V., Pelizzetti E., Ajassa R., Carlotti M.E., Vione D. Photochemical processes involving nitrite in surface water samples. Aquatic Sciences. 2007. V. 69(1). P. 71-85.

[10] Chatterjee D., Dasgupta S. // J. Photochem. Photobiol. C. Photochem. Rev. 2005. V. 6. P. 186-205.

[11] El-Bahy Z.M., Ismail A.A. // J. Hazard. Mater. 2009. V. 166. N 1. P. $138-143$.

[12] Zavastin D.E., Gherman S., Cretescu I. // Revista de Chimie. 2012. V. 63. P. 1075-1078.

[13] Jaškova V., Hochmannova L., Vytřasová J. // Int. J. Photoenergy. V. 2013 (2013). Article ID 795060. 6 p. doi 10.1155/2013/795060

[14] Chiu W.S., Khiew P.S., Cloke M., Isa D., Tan T.K., Radiman S., Abd-Shukor R., Abd. Hamid M.A., Huang N.M., Lim H.N., Chia C.H. // Chem. Engineering J. 2010. V. 158. P. $345-352$.

[15] Sun J.H., Dong S.Y., Wang Y.K., Sun S.P. // J. Hazard. Mater. 2009. V. 172. P. $1520-1526$.

[16] Li Yang, Zhang Wen, Niu Junfeng, Chen Yongsheng. // ACS Nano. 2012. V. 6. P. 5164-5173. 
[17] Mohamed R.M., Mkhalid I.A., Al-Thabaiti S.A., Mokhtar Mohamed. // J. Nanosci. Nanotechnol. 2013. V. 13. P. $4975-4980$.

[18] Othman I., Tabet M., Farag A. // J. Int. Envir. Appl. Sci. 2012. V. 7. P. $661-672$.

[19] Abbott L.C., Batchelor S.N., Oakes J. // J. Phys. Chem. B. 2004. V. 108. P. 13786-13735.

[20] Evstropiev S.K., Dukelskii K.V., Kislyakov I.M., Evstropyev K.S., Gatchin Yu.A. // Polymers for Adv. Technol. 2016. V. 27. P. $1258-1260$.

[21] Дукельский К.В., Евстропьев С.К. // Оптический журнал. 2011. T. 78. № 3. C. 62-71; Dukel'skii K.V., Evstrop'ev S.K. // J. Opt. Technol. 2011. V. 78. N 3. P. 202-209.

[22] Серова В.Н., Носкова Э.Н. // Вестник Казанского технологического университета. 2016. Т. 19. № 15. С. 61-63.

[23] The Chemistry of Synthetic Dyes / Ed. by Venkataram K.N.Y. London: Acad. Press Inc., 1974. V. 3. Р. 131-240. Перевод: Химия синтетических красителей / Под ред. Венкатарана К. Т. 3. Л.: Химия, 1974. 464 с.

[24] Warneck P., Wurzinger C. // J. Phys. Chem. 1988. V. 52. P. $6278-6283$.

[25] Образцов П.А., Нащекин А.В., Никоноров Н.В., Сидоров А.И., Панбилова А.В., Брунков П.Н. // ФТТ. 2013. T. 55. B. 6. C. $1180-1186$.

[26] Lin Guo, Shihe Yang, Chulei Yang, Ping Yu, Jiannong Wang, Weikun Ge, George K.L. Wong // Appl. Phys. Lett. 2000. V. 76. P. 2901-2903. 